\title{
Blood transfer devices for malaria rapid diagnostic tests: evaluation of accuracy, safety and ease of use
}

Heidi Hopkins ${ }^{*}$, Wellington Oyibo², Jennifer Luchavez ${ }^{3}$, Mary Lorraine Mationg ${ }^{3}$, Caroline Asiimwe ${ }^{1}$, Audrey Albertini ${ }^{4}$, Iveth J González ${ }^{4}$, Michelle L Gatton ${ }^{5}$, David Bell ${ }^{4,6}$

\begin{abstract}
Background: Malaria rapid diagnostic tests (RDTs) are increasingly used by remote health personnel with minimal training in laboratory techniques. RDTs must, therefore, be as simple, safe and reliable as possible. Transfer of blood from the patient to the RDT is critical to safety and accuracy, and poses a significant challenge to many users. Blood transfer devices were evaluated for accuracy and precision of volume transferred, safety and ease of use, to identify the most appropriate devices for use with RDTs in routine clinical care.

Methods: Five devices, a loop, straw-pipette, calibrated pipette, glass capillary tube, and a new inverted cup device, were evaluated in Nigeria, the Philippines and Uganda. The 227 participating health workers used each device to transfer blood from a simulated finger-prick site to filter paper. For each transfer, the number of attempts required to collect and deposit blood and any spilling of blood during transfer were recorded. Perceptions of ease of use and safety of each device were recorded for each participant. Blood volume transferred was calculated from the area of blood spots deposited on filter paper.

Results: The overall mean volumes transferred by devices differed significantly from the target volume of 5 microliters $(p<0.001)$. The inverted cup (4.6 microliters) most closely approximated the target volume. The glass capillary was excluded from volume analysis as the estimation method used is not compatible with this device. The calibrated pipette accounted for the largest proportion of blood exposures (23/225, 10\%); exposures ranged from $2 \%$ to $6 \%$ for the other four devices. The inverted cup was considered easiest to use in blood collection (206/ 226, 91\%); the straw-pipette and calibrated pipette were rated lowest (143/225 [64\%] and 135/225 [60\%] respectively). Overall, the inverted cup was the most preferred device $(72 \%, 163 / 227)$, followed by the loop (61\%, 138/227).
\end{abstract}

Conclusions: The performance of blood transfer devices varied in this evaluation of accuracy, blood safety, ease of use, and user preference. The inverted cup design achieved the highest overall performance, while the loop also performed well. These findings have relevance for any point-of-care diagnostics that require blood sampling.

\section{Background}

Malaria rapid diagnostic tests (RDTs) are recommended for use in areas where good-quality microscopy is not available, including peripheral health centers and community-based case management programmes [1,2]. RDTs are, therefore, increasingly used by personnel with

\footnotetext{
* Correspondence: heidi.hopkins@finddiagnostics.org

'Foundation for Innovative New Diagnostics, Lumumba Avenue, Kampala, Uganda

Full list of author information is available at the end of the article
}

minimal training in laboratory techniques. To maintain test accuracy and utility in such settings the tests must be as simple, safe and reliable as possible. Previous studies have demonstrated that health workers with minimal formal training can satisfactorily perform and interpret RDTs, even with earlier and more complicated test formats [3-6]. However, reports and anecdotal observation have repeatedly indicated that blood transfer is an aspect of RDT use that poses a significant challenge to many users [7-12].

\section{Biomed Central}

(c) 2011 Hopkins et al; licensee BioMed Central Ltd. This is an Open Access article distributed under the terms of the Creative Commons Attribution License (http://creativecommons.org/licenses/by/2.0), which permits unrestricted use, distribution, and reproduction in any medium, provided the original work is properly cited. 
Most commercially available RDT kits are packaged with individual-use disposable blood transfer devices intended to collect, transfer and deposit a fixed volume of blood (typically 5 or 10 microliters) from a fingerprick to the absorbent pad within a well on the RDT cassette. Available transfer devices include loops, strawpipettes, squeezable calibrated pipettes and capillary tubes. Blood transfer devices should fulfill a number of basic requirements: first, they should transfer the correct volume of blood (avoiding inaccurate test results); second, the risk of exposure of the user to direct blood contact through design, poor technique or accident should be minimized; and third, they should be easy to manipulate [13].

As RDT cassette design is fairly standardized, the parameters governing the appropriateness of design of the transfer device should be common to various RDT kits. Identifying the best design should therefore improve the overall diagnostic accuracy and safety of all RDT cassettes. Five devices were evaluated: four were typical examples of the main types of devices currently provided with commercially-available malaria RDTs, while the fifth was developed specifically for the study, based on an earlier promising design that had not been deployed with commercially-available tests. The study reported here evaluated blood transfer devices in terms of accuracy and consistency of blood volume transferred, blood safety, and ease of use in the hands of health workers, to identify the most appropriate blood transfer devices for use with malaria RDTs in routine clinical care.

\section{Methods \\ Study participants}

The study was conducted between August and November 2009 among 227 health workers in Nigeria, the Philippines and Uganda, drawn from staff of front-line health centers and community-based malaria programmes. Staff members with a patient care role were invited to participate irrespective of previous experience with RDTs, but information on previous experience with RDTs and blood transfer was recorded. Participants were unaware of the provenance of the devices evaluated, in order to avoid biasing the results. All participants provided written informed consent. The study protocol was approved by institutional review boards in each participating country.

\section{Devices evaluated}

The five blood transfer devices evaluated were the loop (hard plastic), straw-pipette (soft plastic), inverted cup (hard plastic), calibrated pipette (soft plastic), and capillary tube (glass), as shown in Figure 1. All except the inverted cup are currently packaged with various brands

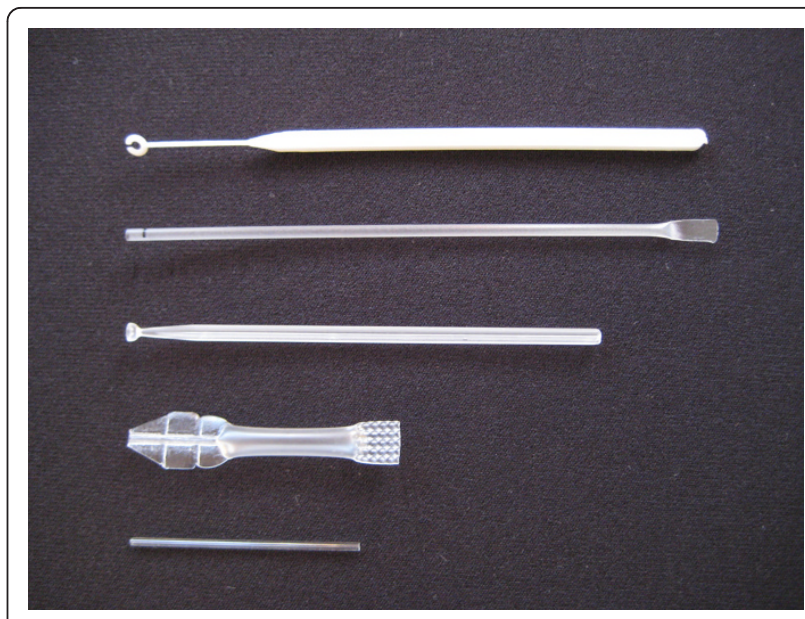

Figure 1 Photograph of blood transfer devices evaluated. From top to bottom, the loop, straw-pipette, inverted cup, calibrated pipette, and glass capillary.

of commercially available RDTs that require a 5 microliter $(\mu \mathrm{L})$ blood sample, while the inverted cup was manufactured for the study to a $5 \mu \mathrm{L}$ design. The inverted cup consists of a concave "cup" $3 \mathrm{~mm}$ in diameter by $0.8 \mathrm{~mm}$ in depth, attached to a handle $8 \mathrm{~cm}$ long (Figure 1). The inverted cup device used in this study is made of polymethyl methacrylate. When applied to a sample of fresh or anticoagulated whole blood, the cup collects and retains blood by capillary action.

\section{Observed use of blood transfer devices}

Prior to the evaluation, study staff demonstrated the correct use of each device to participating health workers, and allowed time for questions. Each participant then used each device under the observation of study staff, who recorded information on ease of use (blood collection, transfer and deposit) and safety (unintentional release of blood and blood exposure) using a checklist. A single sample of fresh venous blood in EDTA, pre-screened for infectious agents, was provided each day. To simulate collection and transfer of fingerprick blood whilst ensuring standardization, study staff pipetted 8-10 $\mu \mathrm{L}$ of venous blood onto a gloved finger. After five practice transfers with each device, each participant was observed using three devices of each type to transfer blood from the gloved finger to absorbent filter paper (Whatman grade 3) to simulate the absorbent pad of an RDT. Transfer devices were presented to each health worker in a computer-generated randomized order.

For each transfer attempt, the observer recorded whether a participant required more than one attempt to collect the desired amount of blood; whether blood was released unintentionally from the device at any time 
before reaching the target; whether the health worker required more than one attempt to deposit all the blood in the target area; and whether blood touched the health worker's gloves, skin or clothing at any time.

\section{Participant perceptions of utility}

After each health worker had been observed transferring blood three times with all five devices, s/he was interviewed using a standard questionnaire regarding ease of collection, transfer and deposition of blood, and the perceived risk of blood exposure. Each health worker ranked the devices in order of preference and stated reasons for her/his choices.

\section{Measurement of transfer volume}

The blood spots were dried and scanned, the area of each was measured using LineScale Plug-In version 1.80 (LineType Software Inc) [14] and the corresponding volume estimated using an area-to-volume coefficient generated each day from reference spots (below).

This method of volume estimation was used for four of the devices evaluated (loop, straw-pipette, calibrated pipette and inverted cup). However, the filter paper used in this assessment does not consistently draw blood from the glass capillary, and consequently a variable amount of blood remains in the capillary and the resulting blood spots do not accurately reflect its transfer volume; this phenomenon was confirmed with additional laboratory work at the Research Institute for Tropical Medicine (RITM) in the Philippines. Briefly, the full capacity of the glass capillary device was measured using a micropipettor and found to be $10 \mu \mathrm{L}$. Glass capillary devices were filled with EDTA-preserved blood and held steadily to RDT pads $(n=50)$ or filter paper $(n=50)$ for 10 seconds. The height of the blood column in each device was measured before and after the 10-second deposition time, and the difference was used to calculate the volume deposited onto each of the two surfaces. From a full starting volume of $10 \mu \mathrm{L}$, the mean volume transferred to the RDT pad was $6.59 \mu \mathrm{L}$, while the mean transferred to filter paper $2.23 \mu \mathrm{L}$, indicating a significant difference in the capacity of the two surfaces to wick blood out of the capillary tube. Therefore, the glass capillary results were disregarded from the analysis of blood volume transferred.

\section{Generation of reference blood spots and estimation of volumes transferred}

Each day fresh venous blood was preserved in EDTA and study staff used a micropipette to make 20 reference blood spots of $5 \mu \mathrm{L}$ each on filter paper. The area of each reference spot was measured with the LineScale software as above, and the mean was used as an area-to-volume coefficient for all spots produced that day from the same blood sample, ensuring that variations in haematocrit or other characteristics of the blood sample that could affect absorbance on filter paper did not bias results.

\section{Data management and statistical analysis}

Data were entered into a central database using Epi-Info version 6.04 (Centers for Disease Control and Prevention, Atlanta, GA) and Microsoft Office Excel 2007, and analysed with Stata version 9 (Stata Corporation, College Station, TX). Proportions for each endpoint were calculated independently for each site and for all sites combined. Repeated measures ANOVA was used to test for differences in mean blood volume transferred between and within individuals. Mean volumes transferred were compared to the goal volume of $5 \mu \mathrm{L}$ using a one-sample t-test. These analyses were performed in SAS version 9 (SAS Institute Inc.).

\section{Results}

\section{Health worker participants}

All participants in the Philippines were voluntary community health workers ("barangay health workers"); those in Nigeria included community health workers and facility-based health workers; most Ugandan participants were health workers employed at peripheral government health centers while the remainder were volunteer community health workers (Table 1). A majority of participants in Uganda $(65 / 74,88 \%)$ had previous experience with at least one of the devices, usually the loop, while prior experience with any blood transfer device was less common among participants in Nigeria and the Philippines (Table 1).

\section{Accuracy and precision of blood volume transferred}

Blood volumes transferred using each device are presented in Table 2 and Figure 2. Values shown in the table are those obtained when the transfers made with each device by each health worker (three transfers per health worker per device) are aggregated (i.e. the unit of analysis is each health worker); there were no significant "within health worker" effects in the repeated measures ANOVA ( $p>0.3)$. The glass capillary is disregarded from this analysis (see Methods). Of the remaining four devices, the average volume deposited by the inverted cup $(4.6 \mu \mathrm{L})$ most closely approximated the desired volume of $5 \mu \mathrm{L}$; the loop delivered slightly less (mean $4.3 \mu \mathrm{L}$ ), while the straw-pipette and calibrated pipette delivered more (mean $5.9 \mu \mathrm{L}$ and $6.2 \mu \mathrm{L}$, respectively). There was significant variation in mean volumes deposited by each device among the Ugandan, Philippine and Nigerian sites. All mean blood volumes deposited differed significantly from the desired volume of $5 \mu \mathrm{L}(\mathrm{p}<$ 0.001) with the exception of the inverted cup in Uganda, loop in Uganda and straw-pipette in Nigeria $(\mathrm{p}>0.1)$. 
Table 1 Baseline characteristics of participating health workers

\begin{tabular}{|c|c|c|c|c|}
\hline & Nigeria & Philippines & Uganda & Combined \\
\hline Total participants & 78 & 75 & 74 & 227 \\
\hline Dates & Oct 2009 & Oct - Nov 2009 & Aug, Nov 2009 & - \\
\hline Health worker category & $\begin{array}{l}78(100 \%) \text { facility-based } \\
\text { clinical staff }\end{array}$ & $\begin{array}{l}75(100 \%) \text { village health } \\
\text { workers }\end{array}$ & $\begin{array}{l}59(80 \%) \text { facility-based clinical } \\
\text { staff; } \\
15(20 \%) \text { voluntary/community } \\
\text { workers }\end{array}$ & - \\
\hline $\begin{array}{r}\text { Had used any blood transfer device before } \\
\text { evaluation date }\end{array}$ & $13(17 \%)$ & $8(11 \%)$ & $65(88 \%)$ & $86(39 \%)$ \\
\hline Used loop before & 0 & $1(1 \%)$ & $65(88 \%)$ & $66(29 \%)$ \\
\hline Used straw-pipette before & 0 & $1(1 \%)$ & $21(28 \%)$ & $22(10 \%)$ \\
\hline Used glass capillary before & $10(13 \%)$ & $3(4 \%)$ & $8(11 \%)$ & $21(9 \%)$ \\
\hline Used calibrated pipette before & $1(1 \%)$ & $3(4 \%)$ & $33(45 \%)$ & $37(16 \%)$ \\
\hline Used inverted cup before & $2(3 \%)$ & 0 & 0 & $2(1 \%)$ \\
\hline Used other device before & 0 & 0 & $5(7 \%)$ & $5(2 \%)$ \\
\hline
\end{tabular}

\section{Ease of use and blood safety}

Overall, more than one-third of the health workers required at least one repeat attempt to collect blood with the loop $(86 / 226,38 \%)$, the straw-pipette $(97 / 224$, $43 \%)$ and the calibrated pipette $(91 / 226,40 \%)$, while the other two devices required fewer repeat attempts (25/ 225 [11\%], and 18/221 [8\%] for the glass capillary and inverted cup respectively, Table 3 ). There were few instances of inadvertent release of blood during transfer, with the highest number occurring with the calibrated pipette $(9 / 226$ [4\%], all in Nigeria). The glass capillary required the highest number of repeated attempts at deposition or release of blood (60\%), though this may have been due in part to the use of filter paper rather than the more absorbent pad used in some RDTs (see Methods). The use of the calibrated pipette accounted for the largest number of blood exposures (23/225, $10 \%)$; exposures ranged from $2 \%$ to $6 \%$ for the other four devices (Table 3). Observed difficulty in device manipulation varied between sites, with the Ugandan participants recorded as having the least difficulties overall.

Opinions of health workers on ease of use, risk of blood exposure, and appropriateness of each device are summarized in Table 4 . The inverted cup was considered easiest to use in blood collection (206/226, 91\%); while the straw-pipette and calibrated pipette were ranked lowest $(143 / 225$ [64\%] and 135/225 [60\%]

Table 2 Accuracy and precision of blood volumes transferred by health workers with each device

\begin{tabular}{|c|c|c|c|c|c|c|c|c|}
\hline & \multicolumn{2}{|c|}{$\begin{array}{l}\text { Nigeria } \\
78 \text { users }\end{array}$} & \multicolumn{2}{|c|}{$\begin{array}{l}\text { Philippines } \\
75 \text { users }\end{array}$} & \multicolumn{2}{|c|}{$\begin{array}{l}\text { Uganda } \\
74 \text { users }\end{array}$} & \multicolumn{2}{|c|}{$\begin{array}{c}\text { All Sites Combined } \\
227 \text { users }\end{array}$} \\
\hline & $\begin{array}{c}\text { Volume in } \mu \mathrm{L}^{\mathrm{a}} \\
\text { mean (std dev), } \\
\text { range }\end{array}$ & $p$-value ${ }^{c}$ & $\begin{array}{l}\text { Volume in } \mu \mathrm{L}^{\mathrm{a}} \\
\text { mean (std dev), } \\
\text { range }\end{array}$ & $p$-value ${ }^{c}$ & $\begin{array}{l}\text { Volume in } \mu \mathrm{L}^{\mathrm{a}} \\
\text { mean (std dev), } \\
\text { range }\end{array}$ & $p$-value ${ }^{c}$ & $\begin{array}{l}\text { Volume in } \mu \mathrm{L}^{\mathrm{a}} \\
\text { mean (std dev), } \\
\text { range }\end{array}$ & $p$-value ${ }^{c}$ \\
\hline LOOP & $\begin{array}{c}\mathbf{4 . 2 1 9} \\
(0.603) \\
2.803-5.804\end{array}$ & $<0.0001$ & $\begin{array}{c}\mathbf{3 . 8 4 2} \\
(0.607) \\
2.597-5.312\end{array}$ & $<0.0001$ & $\begin{array}{c}\mathbf{4 . 8 4 1} \\
(0.968) \\
2.845-9.306\end{array}$ & 0.1611 & $\begin{array}{c}\mathbf{4 . 2 9 7} \\
(0.846) \\
2.597-9.306\end{array}$ & $<0.0001$ \\
\hline STRAW-PIPETTE & $\begin{array}{c}\mathbf{5 . 0 0 4} \\
(1.191) \\
1.796-7.602 \\
\end{array}$ & 0.9768 & $\begin{array}{c}\mathbf{5 . 7 7 8} \\
(1.199) \\
2.922-9.551 \\
\end{array}$ & $<0.0001$ & $\begin{array}{c}7.042 \\
(1.671) \\
2.038-9.469 \\
\end{array}$ & $<0.0001$ & $\begin{array}{c}\mathbf{5 . 9 2 4} \\
(1.601) \\
1.796-9.551 \\
\end{array}$ & $<0.0001$ \\
\hline $\begin{array}{r}\text { GLASS } \\
\text { CAPILLARY }\end{array}$ & - & - & - & - & - & - & - & - \\
\hline $\begin{array}{r}\text { CALIBRATED } \\
\text { PIPETTE }\end{array}$ & $\begin{array}{c}\mathbf{5 . 8 7 5} \\
(1.597) \\
2.259-10.287\end{array}$ & $<0.0001$ & $\begin{array}{c}\mathbf{5 . 6 4 9} \\
(1.437) \\
2.681-10.406\end{array}$ & 0.0002 & $\begin{array}{c}7.086 \\
(1.507) \\
3.444-11.855\end{array}$ & $<0.0001$ & $\begin{array}{c}\mathbf{6 . 1 9 5} \\
(1.635) \\
2.259-11.855\end{array}$ & $<0.0001$ \\
\hline INVERTED CUP & $\begin{array}{c}\mathbf{4 . 5 2 5} \\
(0.683) \\
2.371-5.885\end{array}$ & $<0.0001$ & $\begin{array}{c}\mathbf{4 . 1 3 9} \\
(0.958) \\
2.874-7.202\end{array}$ & $<0.0001$ & $\begin{array}{c}\mathbf{5 . 0 8 8} \\
(0.824) \\
3.499-7.382\end{array}$ & 0.3633 & $\begin{array}{c}\mathbf{4 . 5 8 1} \\
(0.910) \\
2.371-7.382\end{array}$ & $<0.0001$ \\
\hline
\end{tabular}

a Estimated from the areas of individual blood spots made by transferring blood to absorbent filter paper.

b The glass capillary is excluded from this analysis because the filter paper surface used in this study does not consistently draw blood from the capillary device, and consequently the resulting blood spots do not accurately reflect its transfer volume.

c Comparison of mean volume with goal volume of 5 microliters $(\mu \mathrm{L})$. 


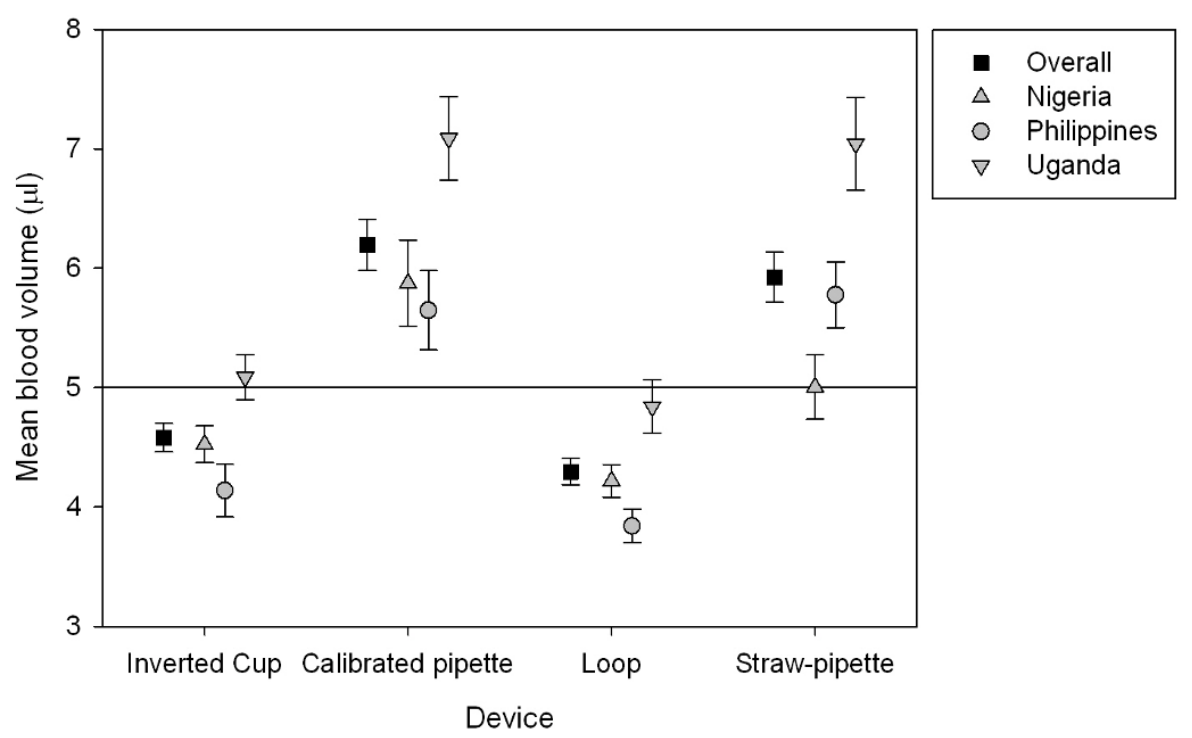

Figure 2 Blood volumes transferred by each device. Squares, triangles and circles represent total and site-specific mean average volumes. Whiskers represent $95 \%$ confidence intervals. NB: The glass capillary is excluded from this analysis because the filter paper surface used in this study does not consistently draw blood from the capillary device, and consequently the resulting blood spots do not accurately reflect its transfer volume.

respectively). All devices except for the glass capillary ranked highly in ease of deposition, with the inverted cup and loop rated easiest by $93 \%$ (211 and 210 out of 226 , respectively). A relatively low proportion of participants perceived a risk of blood exposure with the inverted cup (12/224, 5\%); those perceiving risk for the other devices ranged from $14 \%$ to $22 \%$ (Table 4 ). The inverted cup was considered "appropriate for health workers to use in patient care" by a large majority of participants $(210 / 225,93 \%)$, followed by the loop with 79\% (178/226) (Table 4). More detailed explanations given by health workers for their responses are presented on-line in Additional file 1, Table S1.

\section{Health workers' preferences}

Ranking of devices by health workers as 'best' and 'worst' for use with malaria RDTs provided similar results (Table 5). The inverted cup was most preferred (72\%, 163/227), followed by the loop $(61 \%, 138 / 227)$. The glass capillary was least preferred $(40 \%, 90 / 227)$. In general, the inverted cup and loop were preferred on the basis of ease and speed of blood collection and deposition and a perceived low risk of blood exposure (Table 5).

\section{Discussion}

As reliability, blood safety, and ease of use of RDT test kits will be fundamental to the success of large-scale implementation of parasite-based diagnosis, optimizing blood transfer devices is important. The five blood transfer devices assessed here, four of which are representative of the devices commonly used with commerciallyavailable malaria RDTs, and one of a more novel design, exhibited a wide range of performance characteristics.

In this study, the inverted cup device provided the best overall performance, and was considered the most appropriate choice for use with RDTs by the majority of participating health workers. The loop also performed well, with similar accuracy and precision of blood volumes transferred but slightly lower scores for other characteristics. The other devices evaluated, including a squeezable straw-pipette, squeezable plastic calibrated pipette, and glass capillary, provided lower accuracy and precision in blood transfer, higher risk of blood exposure, and lower scores on ease-of-use assessment and user preference. The main advantages of the cup design appear to result from the ease of uptake or collection of blood (achieved by contact with the blood drop surface) and presentation of a broad surface area of retained blood for release onto the absorbent surface. In contrast, the loop presents a narrow contact surface unless tilted sideways (which some participants noted is more challenging when depositing blood into the well of an RDT rather than onto the flat surface of the filter paper used in this evaluation). The straw-pipette and calibrated pipette also required further manipulation to ensure contact between the blood and the absorbent surface.

The need for improved blood transfer methods for use with RDTs has been identified in previous reports [7-12]. The only previously published direct comparison of 
Table 3 Observation of health workers' use of devices for blood collection, transfer and deposition

\begin{tabular}{|c|c|c|c|c|}
\hline & $\begin{array}{l}\text { Nigeria } \\
\mathrm{n}=78^{\mathrm{a}}\end{array}$ & $\begin{array}{c}\text { Philippines } \\
\mathrm{n}=75^{\mathrm{a}}\end{array}$ & $\begin{array}{l}\text { Uganda } \\
\mathrm{n}=74^{\mathrm{a}}\end{array}$ & $\begin{array}{c}\text { Combined } \\
\mathrm{n}=227^{\mathrm{a}}\end{array}$ \\
\hline & \multicolumn{4}{|c|}{ Number (\%) observed "Yes" for any of the health worker's 3 transfers per device } \\
\hline \multicolumn{5}{|l|}{$\geq 1$ failed attempt to collect blood } \\
\hline LOOP & $21 / 77(27 \%)$ & $49 / 74(66 \%)$ & $16(22 \%)$ & $86 / 225(38 \%)$ \\
\hline STRAW-PIPETTE & $43 / 77(56 \%)$ & $32 / 73(44 \%)$ & $22(30 \%)$ & $97 / 224(43 \%)$ \\
\hline GLASS CAPILLARY & 13/77 (17\%) & $8 / 74(11 \%)$ & $4(5 \%)$ & $25 / 225(11 \%)$ \\
\hline CALIBRATED PIPETTE & $54(69 \%)$ & $23 / 74(31 \%)$ & $14(19 \%)$ & $91 / 226(40 \%)$ \\
\hline INVERTED CUP & $3 / 75(4 \%)$ & 14/72 (19\%) & $1(1 \%)$ & 18/221 (8\%) \\
\hline \multicolumn{5}{|l|}{ Blood released unintentionally during transfer } \\
\hline LOOP & 0/76 & $1 / 73(1 \%)$ & $1(1 \%)$ & $2 / 223(1 \%)$ \\
\hline STRAW-PIPETTE & $1 / 76(1 \%)$ & $0 / 73$ & $1(1 \%)$ & $2 / 223(1 \%)$ \\
\hline GLASS CAPILLARY & $2 / 76(3 \%)$ & $1 / 73(1 \%)$ & 0 & $3 / 223(1 \%)$ \\
\hline CALIBRATED PIPETTE & $9(12 \%)$ & $0 / 74$ & 0 & 9/226 (4\%) \\
\hline INVERTED CUP & $0 / 75$ & $0 / 72$ & $1(1 \%)$ & $1 / 221(0.5 \%)$ \\
\hline \multicolumn{5}{|l|}{$\geq 1$ failed attempt to deposit blood } \\
\hline LOOP & $7 / 75(9 \%)$ & $17 / 73(23 \%)$ & $4(5 \%)$ & $28 / 222(13 \%)$ \\
\hline STRAW-PIPETTE & $24 / 77(31 \%)$ & $12 / 73(16 \%)$ & $11(15 \%)$ & $47 / 224(21 \%)$ \\
\hline GLASS CAPILLARY ${ }^{b}$ & $78(100 \%)$ & $35 / 73(48 \%)$ & $23(31 \%)$ & $136 / 225(60 \%)$ \\
\hline CALIBRATED PIPETTE & $16 / 77(21 \%)$ & $11 / 74(15 \%)$ & $9 / 74(12 \%)$ & $36 / 225(16 \%)$ \\
\hline INVERTED CUP & $13 / 72(18 \%)$ & $28 / 71(39 \%)$ & $8(11 \%)$ & $49 / 217(23 \%)$ \\
\hline \multicolumn{5}{|l|}{ Health worker exposed to blood } \\
\hline LOOP & $12 / 77(16 \%)$ & $1 / 72(1 \%)$ & 0 & $13 / 223(6 \%)$ \\
\hline STRAW-PIPETTE & $7 / 76(9 \%)$ & $3 / 70(4 \%)$ & $2 / 73(3 \%)$ & $12 / 219(5 \%)$ \\
\hline GLASS CAPILLARY & $3 / 73(4 \%)$ & $5 / 72(7 \%)$ & $1(1 \%)$ & $9 / 219(4 \%)$ \\
\hline CALIBRATED PIPETTE & 18/77 (23\%) & $3 / 74(4 \%)$ & $2(3 \%)$ & $23 / 225(10 \%)$ \\
\hline INVERTED CUP & $4 / 74(5 \%)$ & $0 / 72$ & 0 & $4 / 220(2 \%)$ \\
\hline
\end{tabular}

\footnotetext{
a Where alternative " $\mathrm{n}$ " specified, the balance had blank data in the case record forms.
}

${ }^{b}$ The glass capillary's results for blood deposition were negatively affected by the fact that the filter paper surface used in this study does not consistently draw blood from the capillary device, and therefore it was more difficult for study participants to deposit blood using this device.

malaria RDT blood transfer devices, by Luchavez et al [13], assessed blood volumes and ease of use of devices available at the time and assessed the importance of variation in blood volume to RDT accuracy. Although excess blood did not affect accuracy, it was noted that blood staining of the RDT test strip may obscure test results [13]. Inadequate blood volume is likely to become critical at low parasite densities, when low volume reduces RDT sensitivity. In the assessment by Luchavez et al sensitivity was considerably reduced at parasite densities of 200 parasites $/ \mu \mathrm{L}$ with volumes less than $3 \mu \mathrm{L}$ for RDTs designed for $5 \mu \mathrm{L}$ of blood [13]. In the present study, for all devices at all sites, both the mean volume transferred and the mean minus one standard deviation fell above $3 \mu \mathrm{L}$ (Table 2), although the range fell below $3 \mu \mathrm{L}$ in some cases. The reason for differences among the three sites in volumes transferred is not clear, as identical methods and materials were used at all sites; it may be speculated that differences in blood samples and ambient conditions, or possibly inadvertent differences in technique, may have led to variation in how the blood was absorbed by the filter paper.

A limitation of this evaluation is the somewhat artificial condition created by using absorbent filter paper, rather than RDT pads, for blood deposition. This method allowed us to estimate the blood volumes transferred by each device in the hands of health workers, but provided unreliable results for transfer volume with the glass capillary due to the observed difference in the absorbent qualities of filter paper compared to an RDT pad. The same phenomenon, and the resultant difficulty in depositing blood onto the filter paper from a glass capillary, may also have contributed to health workers' less favorable perception of this device, although many participants also commented on unrelated features. Another artificial condition created for this study was the placement of a blood drop on a gloved finger, rather than pricking a patient's finger, to obtain a source of 
Table 4 Participant questionnaire: ease of use, risk and appropriateness of each device ${ }^{a}$

\begin{tabular}{|c|c|c|c|c|}
\hline & $\begin{array}{l}\text { Nigeria } \\
\mathrm{n}=78^{\mathrm{b}}\end{array}$ & $\begin{array}{c}\text { Philippines } \\
\mathrm{n}=75^{\mathrm{b}}\end{array}$ & $\begin{array}{l}\text { Uganda } \\
\mathrm{n}=73^{\mathrm{bc}}\end{array}$ & $\begin{array}{l}\text { Combined } \\
n=226^{b}\end{array}$ \\
\hline & \multicolumn{4}{|c|}{ Number and (\%) of health workers answering "Yes" } \\
\hline \multicolumn{5}{|l|}{ Easy to collect (pick up) blood } \\
\hline LOOP & $77(99 \%)$ & $30(40 \%)$ & $67(92 \%)$ & $174(77 \%)$ \\
\hline STRAW-PIPETTE & $42(54 \%)$ & $61 / 74(82 \%)$ & $40(55 \%)$ & $143 / 225(64 \%)$ \\
\hline GLASS CAPILLARY & $72(92 \%)$ & $63 / 74(85 \%)$ & $50(68 \%)$ & $185 / 225(82 \%)$ \\
\hline CALIBRATED PIPETTE & $42(54 \%)$ & $61 / 74(82 \%)$ & $32(44 \%)$ & $135 / 225(60 \%)$ \\
\hline INVERTED CUP & $78(100 \%)$ & $57(76 \%)$ & $71(97 \%)$ & $206(91 \%)$ \\
\hline \multicolumn{5}{|l|}{ Easy to release (deposit) blood } \\
\hline LOOP & $78(100 \%)$ & $63(84 \%)$ & $69(95 \%)$ & $210(93 \%)$ \\
\hline STRAW-PIPETTE & $61(78 \%)$ & $68 / 74(92 \%)$ & $61(84 \%)$ & $190 / 225(84 \%)$ \\
\hline GLASS CAPILLARYd & $9(12 \%)$ & $28 / 74(38 \%)$ & $34(47 \%)$ & $71 / 225(32 \%)$ \\
\hline CALIBRATED PIPETTE & $61(78 \%)$ & $68 / 74(92 \%)$ & $66(90 \%)$ & $195 / 225(87 \%)$ \\
\hline INVERTED CUP & $78(100 \%)$ & $65(87 \%)$ & $68(93 \%)$ & $211(93 \%)$ \\
\hline \multicolumn{5}{|l|}{ Risk of blood exposure } \\
\hline LOOP & $1 / 76(1 \%)$ & $22 / 74(30 \%)$ & $9(12 \%)$ & $32 / 223(14 \%)$ \\
\hline STRAW-PIPETTE & $5(6 \%)$ & $7 / 73(10 \%)$ & $19(26 \%)$ & $31 / 224(14 \%)$ \\
\hline GLASS CAPILLARY & $21(27 \%)$ & $11 / 71(15 \%)$ & $17(23 \%)$ & $49 / 222(22 \%)$ \\
\hline CALIBRATED PIPETTE & $14(18 \%)$ & $5 / 73(7 \%)$ & $17(23 \%)$ & $36 / 224(16 \%)$ \\
\hline INVERTED CUP & $0 / 77(0 \%)$ & 10/74 (14\%) & $2(3 \%)$ & $12 / 224(5 \%)$ \\
\hline \multicolumn{5}{|l|}{ Appropriate for health workers to use in patient care } \\
\hline LOOP & 76 (97\%) & $37(49 \%)$ & 65 (89\%) & $178(79 \%)$ \\
\hline STRAW-PIPETTE & $47(60 \%)$ & 63/73 (86\%) & $39(53 \%)$ & $149 / 224$ (67\%) \\
\hline GLASS CAPILLARYd & $22(28 \%)$ & $48 / 71(68 \%)$ & $36(49 \%)$ & 106/222 (48\%) \\
\hline CALIBRATED PIPETTE & $37(47 \%)$ & $63 / 73(86 \%)$ & $36(49 \%)$ & $136 / 224$ (61\%) \\
\hline INVERTED CUP & $78(100 \%)$ & $61 / 74(82 \%)$ & 71 (97\%) & $210 / 225(93 \%)$ \\
\hline
\end{tabular}

blood for each transfer. The devices tested may perform slightly differently when collecting blood from skin rather than the latex surface.

The current study was specifically aimed at assessing the suitability of the devices for use by front-line health workers with limited laboratory training and limited facilities. Some workers may also have lesser capacity for fine manipulation. Clearly, specific training may overcome some of the apparent deficiencies illustrated here. For example, the capillary tube and calibrated pipette may perform better in laboratories with technicians accustomed to manipulating such devices. The results of this study show significant variation between study sites; differences in prior training or experience using certain types of devices are likely explanations for these variations. For example, Ugandan health workers who have considerable experience with RDT use made, in general, fewer observed errors with all devices than did less-experienced participants in the other two countries (Table 3), although patterns across the sites were not always consistent and differences were not often large. Where health workers are already trained and accustomed to a particular device design, the process of change may have a detrimental impact on overall performance, which would outweigh the potential advantages of a new design. However, when considering large-scale implementation of RDTs in remote areas, essential to fulfill the new global WHO policy of parasite-based diagnosis prior to antimalarial treatment, [2] performance, safety and ease of use in the hands of front-line health workers will be critical to success.

As RDT cassette design is essentially standard, blood transfer devices should be an exchangeable accessory. Careful selection of the blood transfer device should be a part of overall RDT kit selection. Flexibility in 
Table 5 Preferences of health workers among devices evaluated, and reasons given

\begin{tabular}{ll}
\hline $\begin{array}{l}\text { Device and number (\%) of health workers } \\
\text { ranking it most or second preferred }\end{array}$ & Representative reasons given for listing device as preferred \\
\hline LOOP 138 (61\%) & "Doesn't waste time, easy to collect, transfer, release and manipulate." \\
"Easy to collect, transfer and deposit with minimal blood exposure risk." \\
"Doesn't require measurement, a single touch collects and deposits the blood, no squeezing \\
is required." \\
"I've used it before, and it's simple to use; also time-saving." \\
"Easily picks the sample; doesn't have sharp edges which could cause fear to the patient."
\end{tabular}

Device and number (\%) of health workers ranking it Representative reasons given for listing device as least preferred least preferred

\begin{tabular}{ll}
\hline LOOP 41 (18\%) & "Difficult in collecting and transferring, might spill blood during transfer." \\
& "Tendency to be spilled and only small amount of blood is obtained." \\
"It's challenging to collect the blood from finger." & "Difficulty in pressure manipulation to collect blood." \\
STRAW-PIPETTE $28(12 \%)$ & "Itakes time to suck the blood since it requires much squeezing." \\
"You may press, as you release, too much blood goes in; difficult to measure blood to the \\
mark"
\end{tabular}
mark."

GLASS CAPILLARY 90 (40\%) "Small and difficult to hold, easily broken."

"It's so automatic that one can't order it to speed up so it does take time."

"Makes picking blood difficult with children because of time duration, and it may break because of brittleness and prick me or my patient."

"So tiny someone with sight problems can find it difficult; you must be careful, it does not give you speed, so you may find your patients lining up."

"It may break injuring the patient or the health worker; it takes time; it may scare children thinking that they may be pricked for the second time."

CALIBRATED PIPETTE $63(28 \%)$

"Only appropriate for people with good sight and steady hands; may not be appropriate for all health workers."

"It has many risks, it can splash blood, it can release before you reach where you want to put blood."

"There's some difficulty, you need some technique to get the blood to the mark, the right amount; and if you have a kid who is fidgeting, you may lose the pressure and the blood goes."

"It has been hard for me to measure here [to the mark]; when I try to draw to the mark, it goes past; when I try to make the blood go down to the mark, it goes all out fast; so it takes time."

INVERTED CUP 5 (2\%)

"Had difficult in collecting blood, small amount goes in."

"Retained the blood samples, I had to bend it if it refused to release blood."

matching the most appropriate RDT (in terms of detection threshold, species detection, stability and cost) to the most appropriate transfer device for the field of intended use could improve the outcome of RDTs' introduction into malaria programmes.
In addition to malaria RDTs, point-of-care tests based on sampling of small quantities of blood or serum are currently used at peripheral health care levels for a number of diseases (e.g. dengue, syphilis), and will be of increasing importance as new tests are developed for 
other diseases. The results of this study are likely to be applicable to these tests, though they should be confirmed on different sample types and with different cadres of health or laboratory worker. It seems illogical to use a wide variety of device designs aimed at achieving essentially the same task, when required transfer volumes are similar, and accuracy, blood safety and ease of use are universally important issues. Establishing quality and consistency in the design of point-of-care diagnostic kits for different diseases will improve both diagnostic performance on the front lines of the health care system and ease of training and implementation.

\section{Conclusions}

The performance of blood transfer devices varied in this evaluation, with the inverted cup design achieving the highest overall performance in terms of accuracy and precision of blood volume transferred, blood safety, ease of use, and user preference, while the loop also performed well in most respects. The relative appropriateness of the different device designs may vary in other settings and in the hands of personnel with different levels of training. These findings have relevance for any point-of-care diagnostics that require blood sampling, and the variability in device performance demonstrated here highlights the need to devote attention to this issue when implementing RDT-based diagnostic programmes.

\section{Additional material}

Additional file 1: Table S1. Explanations given by participants for perceptions of ease of use, risk and appropriateness as summarized in Table 4 in the full manuscript.

\begin{abstract}
Acknowledgements
We would like to thank the field teams and health workers in Nigeria, the Philippines and Uganda for their enthusiastic participation in this study. We greatly appreciate the expertise and diligence of Georges Revillet in generating prototypes of the inverted cup, of Alexandre Hainard at the University of Geneva in assisting with its preliminary laboratory testing, and of Ranald Sutherland in coordinating the design and manufacturing process for this device. The study was funded by the Foundation for Innovative New Diagnostics (FIND), an independent non-profit foundation with headquarters in Geneva, Switzerland, and with field offices in Uganda and India. $\mathrm{HH}, \mathrm{CA}$, AA, IG, and DB are employed by FIND. (DB was formerly in the WHO Global Malaria Programme.) WO is on faculty at University of Lagos. JL and MLM are employed at the Research Institute for Tropical Medicine in the Philippines. MLG is supported by an NHMRC Career Development Award.
\end{abstract}

\section{Author details}

${ }^{1}$ Foundation for Innovative New Diagnostics, Lumumba Avenue, Kampala, Uganda. ${ }^{2}$ Department of Medical Microbiology and Parasitology, College of Medicine, University of Lagos, Idi-Araba, Lagos, Nigeria. ${ }^{3}$ Research Institute for Tropical Medicine, Filinvest Compound, Alabang, Muntinlupa, Philippines. ${ }^{4}$ Foundation for Innovative New Diagnostics, Avenue de Budé, Geneva, Switzerland. ${ }^{5}$ Queensland Institute of Medical Research, Queensland, Australia. ${ }^{6}$ Global Malaria Programme, World Health Organization, Geneva, Switzerland.

\section{Authors' contributions}

$\mathrm{HH}$ designed the study, contributed to development of the inverted cup device, coordinated field work in Uganda, analysed and interpreted the data, and drafted the manuscript. WO contributed to study design and coordinated field work in Nigeria. $J$ and MLM contributed to study design, coordinated field work in the Philippines, and conducted additional laboratory assessments at RITM. CA contributed to study design and participated in critical revision of the manuscript. AA and IG coordinated development of the inverted cup device, contributed to study design and participated in critical revision of the manuscript. MLG performed the statistical analysis for blood volumes transferred and participated in critical revision of the manuscript. DB conceived the study, contributed to development of the inverted cup device, contributed to the study design, and helped to draft and revise the manuscript. All authors read and approved the final manuscript.

\section{Competing interests}

The authors declare that they have no competing interests.

Received: 3 October 2010 Accepted: 8 February 2011

Published: 8 February 2011

\section{References}

1. WHO: The use of rapid malaria diagnostic tests. 2 edition. World Health Organization, Geneva; 2006.

2. WHO: Guidelines for the treatment of malaria. 2 edition. World Health Organization, Geneva; 2010.

3. Premji Z, Minjas JN, Shiff CJ: Laboratory diagnosis of malaria by village health workers using the rapid manual ParaSight-F test. Trans $R$ Soc Trop Med Hyg 1994, 88:418.

4. Bojang KA: The diagnosis of Plasmodium falciparum infection in Gambian children, by field staff using the rapid, manual, ParaSight-F test. Ann Trop Med Parasitol 1999, 93:685-687.

5. Mayxay M, Newton PN, Yeung S, Pongvongsa T, Phompida S, Phetsouvanh R, White NJ: Short communication: An assessment of the use of malaria rapid tests by village health volunteers in rural Laos. Trop Med Int Health 2004, 9:325-329.

6. Bell D, Go R, Miguel C, Walker J, Cacal L, Saul A: Diagnosis of malaria in a remote area of the Philippines: comparison of techniques and their acceptance by health workers and the community. Bull World Health Organ 2001, 79:933-941.

7. Fogg C, Twesigye R, Batwala V, Piola P, Nabasumba C, Kiguli J, Mutebi F, Hook C, Guillerm M, Moody A, Guthmann JP: Assessment of three new parasite lactate dehydrogenase (pan-pLDH) tests for diagnosis of uncomplicated malaria. Trans R Soc Trop Med Hyg 2008, 102:25-31.

8. Harvey SA, Jennings L, Chinyama M, Masaninga F, Mulholland K, Bell DR: Improving community health worker use of malaria rapid diagnostic tests in Zambia: package instructions, job aid and job aid-plus-training. Malar J 2008, 7:160.

9. Roukens AH, Berg J, Barbey A, Visser LG: Performance of self-diagnosis and standby treatment of malaria in international oilfield service employees in the field. Malar J 2008, 7:128.

10. Seidahmed OM, Mohamedein MM, Elsir AA, Ali FT, Malikel FM, Ahmed ES: End-user errors in applying two malaria rapid diagnostic tests in a remote area of Sudan. Trop Med Int Health 2008, 13:406-409.

11. Tavrow P, Knebel E, Cogswell L: Using quality design to improve malaria rapid diagnostic tests in Malawi Published for the United States Agency for International Development (USAID) by the Quality Assurance Project (QAP); 2000.

12. WHO/WPRO: Malaria rapid diagnosis: Making it work 2003.

13. Luchavez J, Lintag ME, Coll-Black M, Baik F, Bell D: An assessment of various blood collection and transfer methods used for malaria rapid diagnostic tests. Malar J 2007, 6:149.

14. Website title [www.linetype.com], LineScale Plug-In version 1.80. LineType Software Inc; 2009.

doi:10.1186/1475-2875-10-30

Cite this article as: Hopkins et al: Blood transfer devices for malaria rapid diagnostic tests: evaluation of accuracy, safety and ease of use. Malaria Journal 2011 10:30. 